\title{
Functional and immunochemical characterisation of different antibodies against the erythropoietin receptor
}

\author{
Agnete Kirkeby ${ }^{\mathrm{a}, *}$, Johan van Beek ${ }^{\mathrm{b}}$, Jacob Nielsen ${ }^{\mathrm{a}}$, Marcel Leist ${ }^{\mathrm{c}}$, Lone Helboe ${ }^{\mathrm{b}}$ \\ a Department of Molecular Neurobiology, H. Lundbeck A/S, Ottiliavej 9, 2500 Valby, Denmark \\ ${ }^{\mathrm{b}}$ Department of Neurobiology, H. Lundbeck A/S, Ottiliavej 9, 2500 Valby, Denmark \\ ${ }^{c}$ Department of Biology, University of Konstanz, Box M657, D-78457 Konstanz, Germany
}

\begin{abstract}
Since it was discovered that the hematopoietic hormone erythropoetin (EPO) exerts neuroprotective effects in the CNS, many studies on the EPO receptor (EPOR) function and localisation in the CNS have been performed. For this purpose, commercially available anti-EPOR antibodies have often been applied. As the literature data on these antibodies show inconsistencies, we here systematically compared six frequently used, commercially available EPOR antibodies for different applications. Five of the antibodies appeared to specifically recognize recombinant rat and human EPOR in HEK293 cells by Western blotting, but the same antibodies yielded different and inconsistent results when human UT-7 cells or rat brain tissue were applied. Immunocytochemical staining of EPOR-transfected HEK cells only produced consistent results with three of the six antibodies. All antibodies stained neurons in rat brain sections, but with large differences in the staining pattern and only the C-20 EPOR antibody was found to label astrocytes. Since EPOR antibodies have been applied in several studies as EPOR antagonists, we further tested the antibodies for their capacity to functionally block the EPO-EPOR interaction in a cellular signalling system with STAT-5 phosphorylation as readout. Here, only the MAB307 antibody showed a partial effect at concentrations of 5-50 $\mu \mathrm{g} / \mathrm{ml}$.
\end{abstract}

(C) 2007 Elsevier B.V. All rights reserved.

Keywords: Erythropoietin receptor; Immunohistochemistry; Immunoblotting; Antibodies; Brain; EPOR antagonist

\section{Introduction}

The EPOR is known to mediate hematopoietic effects of EPO in the bone marrow, however, EPOR expression has also been reported to occur in various parts of the brain, where it is believed to mediate beneficial neurological effects (Brines and Cerami, 2005; Richmond et al., 2005). Indeed, numerous studies have shown an important neuroprotective and neurotrophic role of EPO in the brain during CNS development and pathogenesis (Brines and Cerami, 2005). The neuroprotective role of the EPOR has, however, been questioned by the finding that certain derivatives of EPO display neuroprotective properties similar to EPO, although these derivatives do not activate the classical EPOR (Leist et al., 2004; Savino et al., 2006). In light of this, determination of the expression pattern of the EPOR in the brain before and after brain injury may provide valuable information

\footnotetext{
* Corresponding author at: Department of Disease Biology, H. Lundbeck A/S, Ottiliavej 9, 2500 Valby, Denmark. Tel.: +45 3643 24 87; fax: +45 36438253. E-mail address: agki@lundbeck.com (A. Kirkeby).
}

on the role of this receptor in neuroprotection in vivo. Indeed, a series of studies investigating localisation and modulation of EPOR expression in the brain have been published, and it has been reported that the expression of EPOR in the brain of both rodents, sheep and humans is increased after ischemic insults (Bernaudin et al., 1999; Castillo-Melendez et al., 2005; Sairanen et al., 2006; Siren et al., 2001; Sun et al., 2004; Sola et al., 2005; Wen et al., 2004). These studies often rely on the use of commercially available anti-EPOR antibodies to provide information by immunohistochemistry and immunoblotting. However, we have in our studies become aware that immunohistochemical mapping of EPOR localisation produce diverging results when investigated with different anti-EPO antibodies. We thus sought to investigate the specificity and staining profiles of different anti-EPOR antibodies by using Western blotting and immunocytochemistry on overexpressed and endogenous EPOR, as well as immunohistochemistry on rat brain sections. The EPOR is a type 1 cytokine receptor with a single membrane-spanning domain (D'Andrea et al., 1990). In this study we have compared antibodies that are directed against either the intracellular C-terminal or the extracellular N-terminal part of the receptor. Western blots 
have been carried out on membrane preparations from cells or tissue in order to limit detection to the mature membrane-bound form of the EPOR and avoid detection of the smaller soluble EPOR (Kuramochi et al., 1990).

In addition to immunostaining and immunoblotting, antiEPOR antibodies have been applied in several studies as apparent functional EPOR (Akimoto et al., 2000; Campana et al., 1998; Keswani et al., 2004; Lee et al., 2004; Liu et al., 2006; Martinez-Estrada et al., 2003; Park et al., 2006; Ruscher et al., 2002; Signore et al., 2006; Stuckmann et al., 2003). Antagonistic properties of these antibodies have, however, not been validated, hence we examined here the blocking effects of these antibodies on EPOR signalling.

\section{Materials and methods}

\subsection{Antibodies}

Six different antibodies directed against the EPOR were used for immunoblotting, immunohistochemistry, immunocytochemistry and assays for EPOR blockade. The antibodies used are listed in Table 1. Anti-EPO antibody (MAB287) used in UT-7 signalling assays was from R\&D Systems (Minneapolis, USA).

\subsection{Generation of EPOR overexpressing cells}

The human Epor gene was amplified from human brain RNA using standard RT-PCR procedures and cloned into pCI-neo using EcoR1 and Xba1. The $5^{\prime}$ end of the coding sequence of the rat Epor (nucleotides 1-840) was amplified from total RNA purified from PC12 cells by RT-PCR and inserted into the IMAGE clone AI711156 containing the remaining coding sequence using EcoR1 and the internal Bgl2 site. The entire coding sequence was amplified from this construct using standard $\mathrm{PCR}$ and was inserted into $\mathrm{pCI}$-neo using EcoR1 and Xba1. DNA was transiently transfected into HEK293 cells using lipofectamine 2000 (Invitrogen, CA, USA) according to manufacturer's instructions.

\subsection{Immunoblotting against EPOR}

Western blot analysis was performed on membranes prepared from UT-7 cells, HEK293 cells transfected with the rat or human Epor construct, and from adult Sprague-Dawley rat brain. Cells or tissue were homogenized in $50 \mathrm{mM}$ Tris, $1 \mathrm{mM}$ EGTA, $5 \mathrm{mM} \mathrm{MgCl}_{2}$, pH 7.4 supplemented with a protease inhibitor cocktail for mammalian cell and tissue extracts (Sigma-Aldrich, St. Louis, USA). Cell membranes were isolated as described elsewhere (Helboe et al., 1997). For whole cell lysates, the lysis buffer used was: $1 \%$ Triton X$100,50 \mathrm{mM}$ Tris, $150 \mathrm{mM} \mathrm{NaCl}, 2 \mathrm{mM}$ EGTA supplemented with protease inhibitor cocktail (complete from Roche). Five $\mu \mathrm{g}$ (HEK293 cells), $10 \mu \mathrm{g}$ (UT-7 cell membranes), $20 \mu \mathrm{g}$ (UT-7 whole cell lysates) or $25 \mu \mathrm{g}$ (rat brain) of total protein was loaded per well and separated by SDS-PAGE on a Bis-Tris gel (NuPAGE, Invitrogen). Immunoblotting was carried out using a panel of anti-EPOR antibodies (see Table 1), horseradish peroxidase-conjugated secondary antibodies (antirabbit, Sigma-Aldrich; anti-mouse, anti-sheep and anti-goat: DAKO, Glostrup, Denmark) and the enhanced chemiluminescence (ECL-Plus, Amersham, Little Chalfont, UK). Rainbow molecular weight markers (Amersham) were included on the blot.

\subsection{Immunocytochemistry}

Cells were grown in plastic chamber slides and fixed with $4 \%$ phosphate buffered paraformaldehyde for $10 \mathrm{~min}$. Cells were then washed intensively in PBS. Antibodies were used at optimal dilution in PBS/1\% BSA/0.1\% Tween-20 and incubated for $1 \mathrm{~h}$ at room temperature (see Table 1 for dilutions). Alternatively, unfixed cells were incubated with primary antibodies in the absence of Tween-20 to evaluate cell surface expression of EPOR. After washing, cells were incubated for $1 \mathrm{~h}$ at room temperature with Alexa Fluor 488-conjugated secondary antibody (1:250; Molecular Probes, Eugene, OR).

Table 1

Anti-EPOR antibodies

\begin{tabular}{|c|c|c|c|c|c|c|}
\hline Antibody & Source & Dilution WB & Dilution ICC & Dilution IHC & Epitope & Epitope localisation \\
\hline $\begin{array}{l}\text { M-20, \#sc-697 (rabbit, } \\
\text { polyclonal) }\end{array}$ & Santa Cruz & $1: 400$ & $1: 500$ & $1: 4000+\mathrm{TSA}$ & $\begin{array}{l}\text { Carboxy terminus peptide of } \\
\text { murine EpoR }\end{array}$ & Intracellular \\
\hline $\begin{array}{l}\text { C-20, \#sc-695 (rabbit, } \\
\text { polyclonal) }\end{array}$ & Santa Cruz & $1: 400$ & $1: 500$ & $1: 2000$ & $\begin{array}{l}\text { Carboxy terminus peptide of } \\
\text { human EpoR }\end{array}$ & Intracellular \\
\hline $\begin{array}{l}\text { H-194, \#sc-5624 (rabbit, } \\
\text { polyclonal) }\end{array}$ & Santa Cruz & $1: 200$ & $1: 500$ & 1:1000 & $\begin{array}{l}\text { Amino terminus peptide (aa } \\
21-214 \text { ) of human EpoR }\end{array}$ & Extracellular \\
\hline E3455-22 (sheep, polyclonal) & Nordic Biosite AB & $1: 500$ & $1: 500$ & $1: 500$ & $\begin{array}{l}\text { Sequence from the extracellular } \\
\text { domain of EPOR }\end{array}$ & Extracellular \\
\hline AF-322-PB (goat, polyclonal) & R\&D Systems & $1: 500$ & $1: 500$ & $1: 1000+\mathrm{TSA}$ & $\begin{array}{l}\text { Total soluble recombinant } \\
\text { human EPOR }\end{array}$ & Extracellular \\
\hline MAB307 (mouse, monoclonal) & R\&D Systems & $1: 200,1: 500$ & $1: 100$ & 1:1000 & $\begin{array}{l}\text { Extracellular domain of human } \\
\text { EpoR }\end{array}$ & Extracellular \\
\hline
\end{tabular}

WB: Western blotting, IHC: immunohistochemistry, ICC: immunocytochemistry, TSA: tyramide signal amplification. Santa Cruz Biotechnology, Santa Cruz, CA; Nordic Biosite AB, Täby, Sweden; R\&D Systems, Minneapolis, MN. 


\subsection{Immunohistochemistry}

Animal experiments were conducted in accordance with the Guide for the Care and Use of Laboratory animals, as promulgated by the National Institute of Health, and Danish laws. Adult male Sprague-Dawley rats were anaesthetised with Avertin and perfused via the ascending aorta with PBS/heparine followed by $4 \%$ phosphate buffered paraformaldehyde. The brains were embedded in paraffin and cut into $4 \mu \mathrm{m}$ sections. Sections were deparaffinised and boiled in $10 \mathrm{mM}$ citrate buffer $\mathrm{pH} 6$ in a microwave oven. Prior to immunostaining, endogenous peroxidase was inactivated with $1.5 \% \mathrm{H}_{2} \mathrm{O}_{2}$ and sections were preincubated in $5 \%$ normal swine serum. The sections were incubated overnight at $4{ }^{\circ} \mathrm{C}$ with each of the 6 different anti-EPOR antibodies (see Table 1 for details and dilutions) followed by biotinylated secondary anti-rabbit (1:500; DAKO), anti-mouse (1:500; DAKO), or anti-sheep/goat (1:200, Amersham) antibodies at room temperature for $1 \mathrm{~h}$ and streptavidin-biotin-complex (Vector, Burlingame, CA, USA) for $1 \mathrm{~h}$. Finally, immunostaining was visualised with $0.05 \%$ diaminobenzidine and $0.01 \%$ $\mathrm{H}_{2} \mathrm{O}_{2}$ in PBS. For each antibody the immunostaining was optimised by testing a range of dilutions and also including further amplification by applying biotinylated tyramide (Perkin-Elmer, Boston, MA). Data are shown for the lowest concentration of antibody yielding a positive staining. In parallel, immunohistochemistry was performed on $40 \mu \mathrm{m}$ free-floating cryo-sections and was shown to result in a staining pattern comparable to that obtained in paraffin sections.

\subsection{UT-7 cells}

For study of EPOR signalling we used the human hematopoietic cell line UT-7 (Komatsu et al., 1991). Cells were grown in RPMI 1640 with $10 \%$ fetal calf serum, $5 \mathrm{ng} / \mathrm{ml}$ recombinant human EPO (Dragon Pharmaceuticals, Vancouver, Canada), $100 \mathrm{U} / \mathrm{ml}$ penicillin and $100 \mu \mathrm{g} / \mathrm{ml}$ streptomycin. Before experiments, cells were washed and starved overnight in starvation medium (RPMI 1640, $1 \%$ fetal calf serum, $100 \mathrm{U} / \mathrm{ml}$ penicillin and $100 \mu \mathrm{g} / \mathrm{ml}$ streptomycin). For stimulation of UT-7 cells, recombinant human EPO was used in all experiments.

\subsection{STAT5 phosphorylation assay}

For induction of STAT5 phosphorylation, the UT-7 cells were stimulated for $15 \mathrm{~min}$ with $30 \mathrm{pM}$ EPO. Anti-EPOR antibodies were preincubated with the cells for $30 \mathrm{~min}$ prior to stimulation with EPO and the anti-EPO antibody was preincubated with EPO for $30 \mathrm{~min}$ before addition to the cells. The maximal applied concentration of each antibody is equivalent to a 1:10 dilution of the stock solution. After stimulation, cells were spun down and lysed on ice for $30 \mathrm{~min}$ in lysis buffer (1\% Nonidet P-40, $20 \mathrm{mM}$ Tris- $\mathrm{HCl} \mathrm{pH} 8,137 \mathrm{mM} \mathrm{NaCl}$, $10 \%$ glycerol with the following inhibitors: $1 \mathrm{mM} \mathrm{Na} \mathrm{VO}_{4}$, $4 \mathrm{mM}$ iodoacetamide, $10 \mathrm{mM} \mathrm{NaF}, 1 \mathrm{mM}$ AEBSF and protease inhibitor mix Complete from Roche). Lysates were spun down at $15,000 \times g$ for $10 \mathrm{~min}$, and supernatants were used for Western blotting. Twenty micrograms of protein was loaded per well on 4-12\% gradient Bis-Tris NuPAGE gels for SDS-PAGE (Invitrogen). For immunoblotting, anti-phospho-STAT5 antibody from Cell Signaling (MA, USA, \#9351, dilution 1:1000) and anti- $\beta$-actin antibody from Sigma (A5441, dilution 1:5000) were used together with horseradish peroxidase-conjugated secondary antibodies (DAKO) and the enhanced chemiluminescence (ECL-Plus, Amersham). SeeBlue prestained standards (Invitrogen) were included on the blots. Antibodies used for this assay were submitted to buffer-change using size exclusion G25 spun column chromatography as described elsewhere (Buus et al., 1995) in order to eliminate sodium azide and other potentially toxic substances present in the original buffers.

\section{Results}

\subsection{Recognition of over-expressed human or rat EPOR by Western blotting}

We first tested the ability of the antibodies to recognise the EPOR from over-expressing HEK293 cells in a Western blotting assay. Cells were transfected with either human or rat EPOR, in order to test for possible species-specific recognition of the EPOR. The antibodies M-20, C-20, H-194, E3455-22 and AF322 all recognised a dominant protein band with a molecular weight between 50 and $75 \mathrm{kDa}$ in cells expressing either the rat or the human EPOR (Fig. 1A and B). The MAB307 antibody did not label bands in either preparation, demonstrating that this antibody is not suitable for Western blotting (Fig. 1A and B). None of the antibodies produced bands in untransfected cells. Taken together, these data suggest that the antibodies M-20, C20, H-194, E3455-22 and AF-322 recognize both rat and human recombinant EPOR in Western blots.

\subsection{Recognition of endogenously expressed human EPOR by Western blotting}

For testing the ability of the antibodies to detect endogenously expressed EPOR, we used membrane and whole cell preparations from the human hematopoietic cell line UT-7. When subjecting membranes or whole cell lysates from UT-7 cells to immunoblotting, a variety of proteins of different sizes were detected with each antibody despite optimised washing and blocking conditions (Fig. 1C and D). Several of the antibodies recognised various bands between 50 and $75 \mathrm{kDa}$, and the identity of the EPOR band could therefore only be determined by including a HEK-EPOR control on the blot. M-20 and C-20 both recognised bands at the size of the EPOR, however they also identified additional bands between 50 and $75 \mathrm{kDa}$, which did not correspond to the size of the EPOR. H-194 and the E345522 antibody produced several different bands, including some between 50 and $75 \mathrm{kDa}$, but none seemed to correspond to the size of the EPOR. Only very weak bands appeared in this area with the AF-322 and MAB307 antibodies, but with elongated exposure time, AF-322 seemed to recognise a band of the right size (Fig. 1C). The lack of consistency between the labellings in UT-7 cells indicates that even though antibodies show a clear and specific response in overexpressing cells, they should be used 
(A)

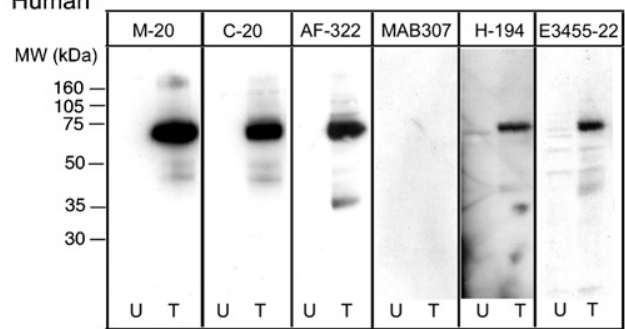

(B)

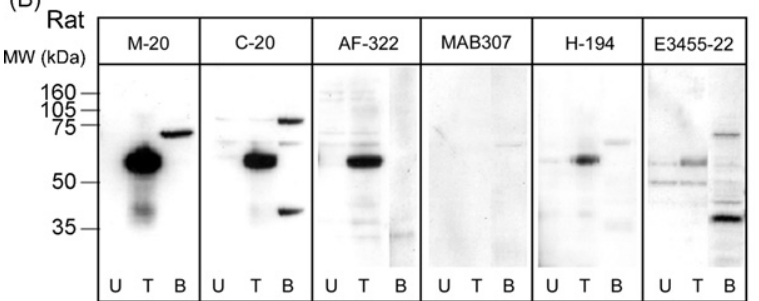

(C)

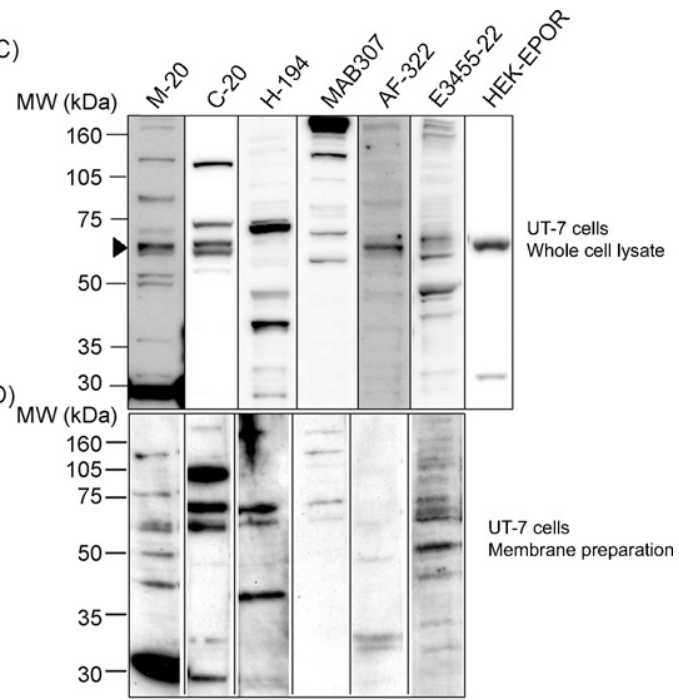

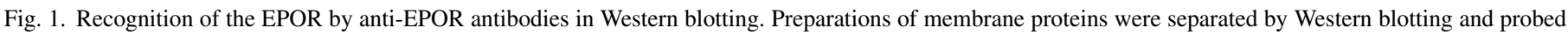

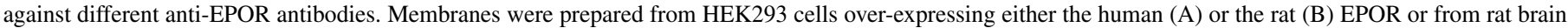

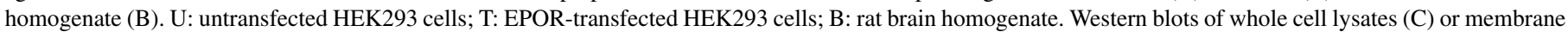

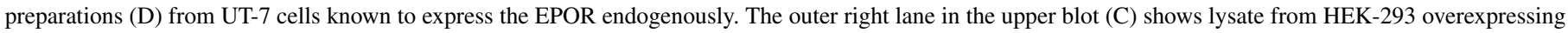
the human EPOR (blotted with M-20). Arrowhead marks the size of the EPOR in HEK293 cells. MW: molecular weight marker.

cautiously when aimed to detect endogenously expressed EPOR in cells and tissues. We suggest an EPOR control (i.e. HEK cells overexpressing the EPOR) is always included on blots.

\subsection{Recognition of EPOR in rat brain homogenate by Western blotting}

Since the EPOR has been reported to be expressed in rat brain, we used this tissue to test whether the antibodies detected specific bands of endogenously expressed brain EPOR. In samples of membranes prepared from total rat brain homogenate, the M20 antibody detected a single protein of higher molecular weight than in HEK293 cells over-expressing the rat EPOR (Fig. 1B). This is most likely not the EPOR, but we cannot exclude the possibility that differences in molecular weight could be explained by tissue-specific glycosylation or processing of the EPOR. The C-20 and E3455-22 antibodies recognised two major bands, migrating above and below that of rat EPOR-transfected cells. However, none of these bands corresponded in size with each other or to the one detected by M-20. As in UT-7 cells, it is therefore not possible by Western blotting to identify one clearly defined band representing the EPOR. One potential explanation for the situation could be that the EPOR is expressed at very low levels in the normal brain. It was not possible to distinguish clearly labelled protein bands in rat brain preparations reacted with MAB307, AF-322 or H-194 (Fig. 1B).

\subsection{Immunocytochemistry on HEK293 cells over-expressing EPOR}

We further tested the antibodies for immunocytochemical staining of HEK293 cells transfected with either human or rat EPOR. The antibodies C-20, M-20 and MAB307 stained both rat and human EPOR-HEK293 permeabilised cells (Fig. 2).
Furthermore, MAB307 antibody stained cell surface EPOR as assessed in unfixed and non-permeabilised cells, confirming that the MAB307 clone recognises an extracellular epitope of the EPOR. C-20 and M-20 recognise intracellular epitopes and as expected failed to stain EPOR in unfixed and non-permeabilised cells (Fig. 2). H-194, E3455-22 and AF-322 antibodies failed to yield consistent staining in EPOR-HEK293 cells both permeabilised and non-permeabilised (data not shown). MAB307, M-20 and C-20 seemed to be EPOR specific in this system, as no staining was observed in non-transfected cells or when the primary antibody was omitted (data not shown).

\subsection{Immunohistochemical staining of rat brain}

We next investigated EPOR staining pattern and cellular localisation in the adult rat brain by use of the different antibodies for immunohistochemistry. Staining of cryosections and paraffin sections resulted in similar staining patterns, and only immunostainings obtained in paraffin sections are shown in Fig. 3. In all cases, no staining was present when the primary antibody was omitted. Staining data obtained with different antibodies showed broad immunoreactivity in neurons of telencephalon, diencephalon, and mesencephalon in the rat brain, and positively stained neurons were found in all areas of the cerebral cortex with all anti-EPOR antibodies used (Fig. 3A). However, staining patterns obtained with the different antibodies differed. While the C-20, H-194, MAB307, AF-322, and E3455-22 antibodies stained most neurons throughout the cortex (Fig. 3A), and the hippocampus (Fig. 3B), staining with the M-20 antibody showed an intense immunoreactivity restricted to a subset of neurons in these areas (Fig. 3A+B). MAB307 broadly stained cortical (Fig. 3A, MAB307), and hippocampal neurons (Fig. 3B, MAB307), as well as cells resembling oligodendrocytes within the corpus callosum (Fig. 3C, MAB307). White matter cells 


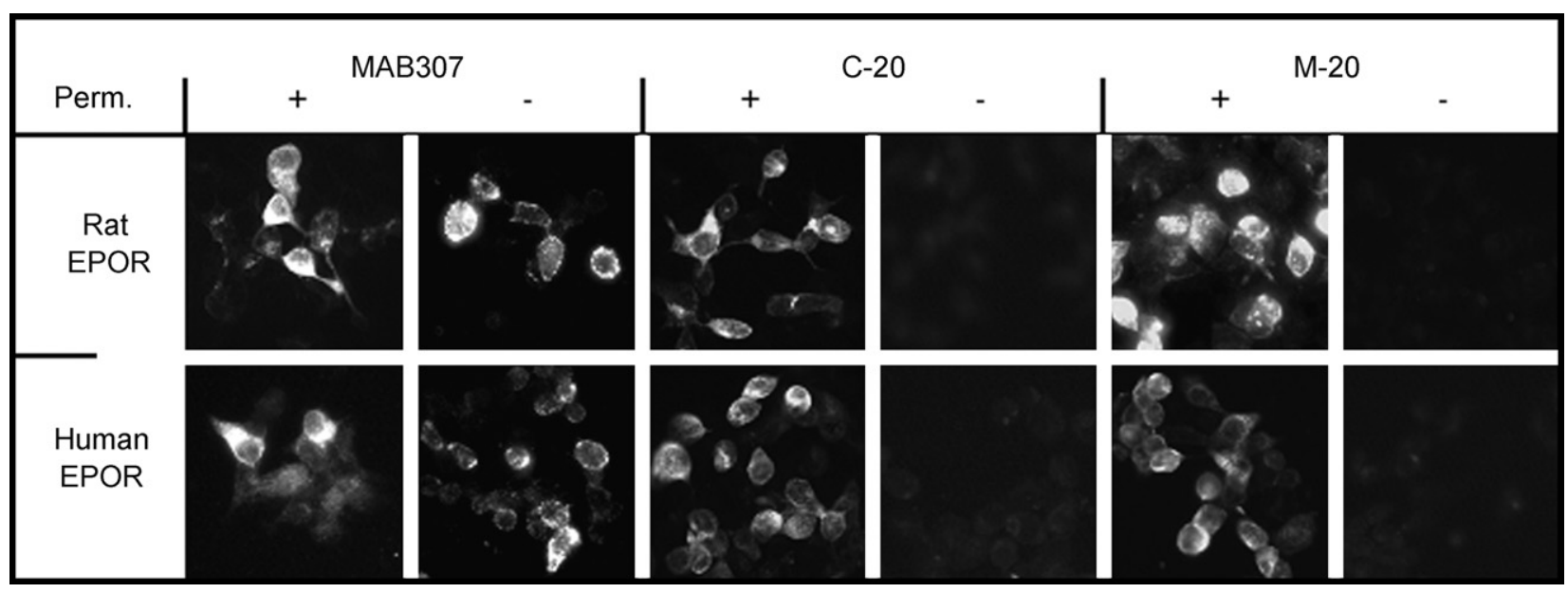

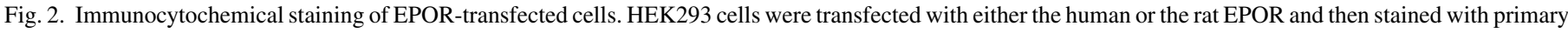

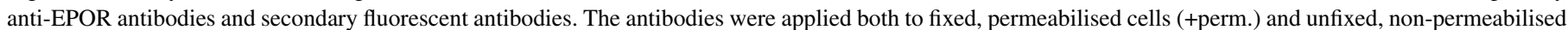
cells (-perm.) Stainings with the H-194, AF-322 and E3455-22 antibodies did not yield consistent staining of EPOR transfected cells in our experiments.

were also labelled by AF-322, whereas the C-20 antibody was found to stain astrocytic cell bodies (Fig. 3C).

At the cellular level, staining also differed between the different EPOR antibodies. Immunostaining with E3455-22, MAB307, C-20 and AF-322 antibodies resulted in a diffuse staining of cytoplasm as well as some nuclear staining (Fig. 3A). M-20 staining was more distinct in the cytoplasm with a granular pattern, whereas H-194 yielded a pronounced punctuate and threadlike cytoplasmic staining (Fig. 3A). For all antibodies, elements of plasma membrane staining may be present, however, it was not possible to clearly distinguish this from the cytoplasmic reactivity. The $\mathrm{C}-20$ antibody occasionally stained single neurons strongly (Fig. 3A+B), but broad neuronal staining was also observed, e.g. in the thalamic nuclei (Fig. 3C). In summary, we observed different patterns of tissue distribution and cellular localisation with the different antibodies, however, we found immunoreactivity to be predominantly in neurons.

\subsection{Inhibition of EPOR signalling}

Since anti-EPOR antibodies have been used as EPOR antagonists in mechanistic studies, we tested the ability of these six antibodies to block EPOR-mediated signalling in UT-7 cells. Signalling through the EPOR was detected as phosphorylation of the transcription factor STAT5, this being part of the EPOR signalling cascade activated by EPO (Wakao et al., 1995). Cells were preincubated with anti-EPOR antibodies and then stimulated with $30 \mathrm{pM}$ EPO for $15 \mathrm{~min}$ at $37^{\circ} \mathrm{C}$ before lysis and analysis by Western blot. It was confirmed that EPO clearly induced increased phosphorylation of STAT5 compared to the control. As a positive control for interruption of the EPO-EPOR interaction we used $10 \mu \mathrm{g} / \mathrm{ml}(67 \mathrm{nM})$ of an anti-EPO antibody, which caused a complete block of STAT5 phosphorylation (Fig. 4A). Among the anti-EPOR antibodies, only MAB307 which is directed against the extracellular domain of the EPOR showed some inhibition of EPO-induced STAT5 phosphorylation. Although this inhibitory effect was seen at $5 \mu \mathrm{g} / \mathrm{ml}(33 \mathrm{nM})$, even $50 \mu \mathrm{g} / \mathrm{ml}(330 \mathrm{nM})$ antibody did not completely abolish
STAT5 phosphorylation (Fig. 4B). We have observed that the MAB307 antibody does not block proliferation of UT-7 cells over a $48 \mathrm{~h}$ time-period at any concentration (data not shown), indicating that inhibition of the short-term EPOR-mediated signalling is not synonymous with a persistent blockade of the receptor. Furthermore, we have found in binding studies on UT-7 cells, that MAB307 does not block the binding of iodinated EPO to the EPOR (data not shown). Thus, MAB307 may trigger an allosteric conformational change of the EPOR resulting in partial inhibition of EPO-induced signal transduction. None of the remaining antibodies (H-194, M-20, C-20, E345522 and AF-322) blocked STAT5 phosphorylation (Fig. 4B-D) or EPO-mediated proliferation (data not shown). The M-20 and C-20 antibodies are directed against the C-terminal intracellular domain of the EPOR, and therefore are not expected to block EPOR activation. H-194, AF-322 and the E3455-22 antibody are directed against the extracellular domain of the receptor, but yet they failed to block EPO-mediated signalling in our assay. It has been shown that certain non-commercial EPOR antibodies could function as EPOR activators, inducing homodimerisation of the receptor (Schneider et al., 1997). However, the antibodies we have tested here were not found to activate signalling through the EPOR (Fig. 4).

\section{Discussion}

We have tested a panel of six different anti-EPOR antibodies for their ability to specifically detect human and rat EPOR by immunoblotting, immunocytochemistry and immunohistochemistry. In Western blotting, all antibodies except the MAB307 detected a single dominant band in HEK293 cells overexpressing the EPOR. Although the MAB307 did not detect EPOR in Western blots, this antibody was shown to block signalling through the EPOR and to stain non-permeabilised unfixed EPOR-transfected cells. This suggests that MAB307 recognises a conformational epitope, thereby making it unsuitable for Western blotting. 
(A)
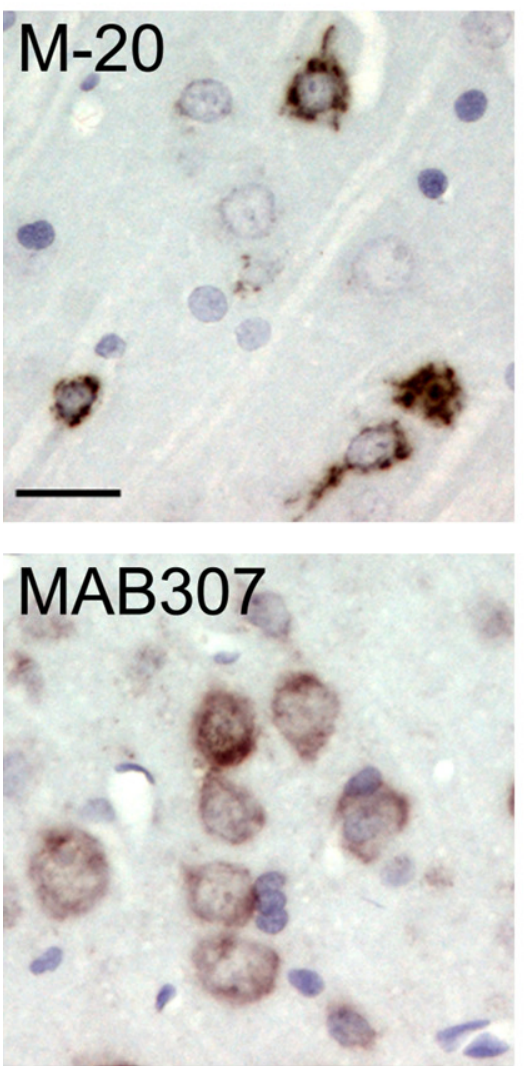

(B)

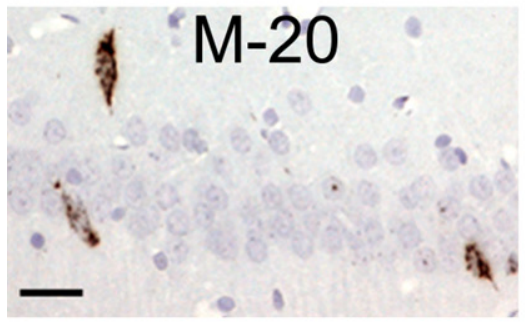

Neocortex
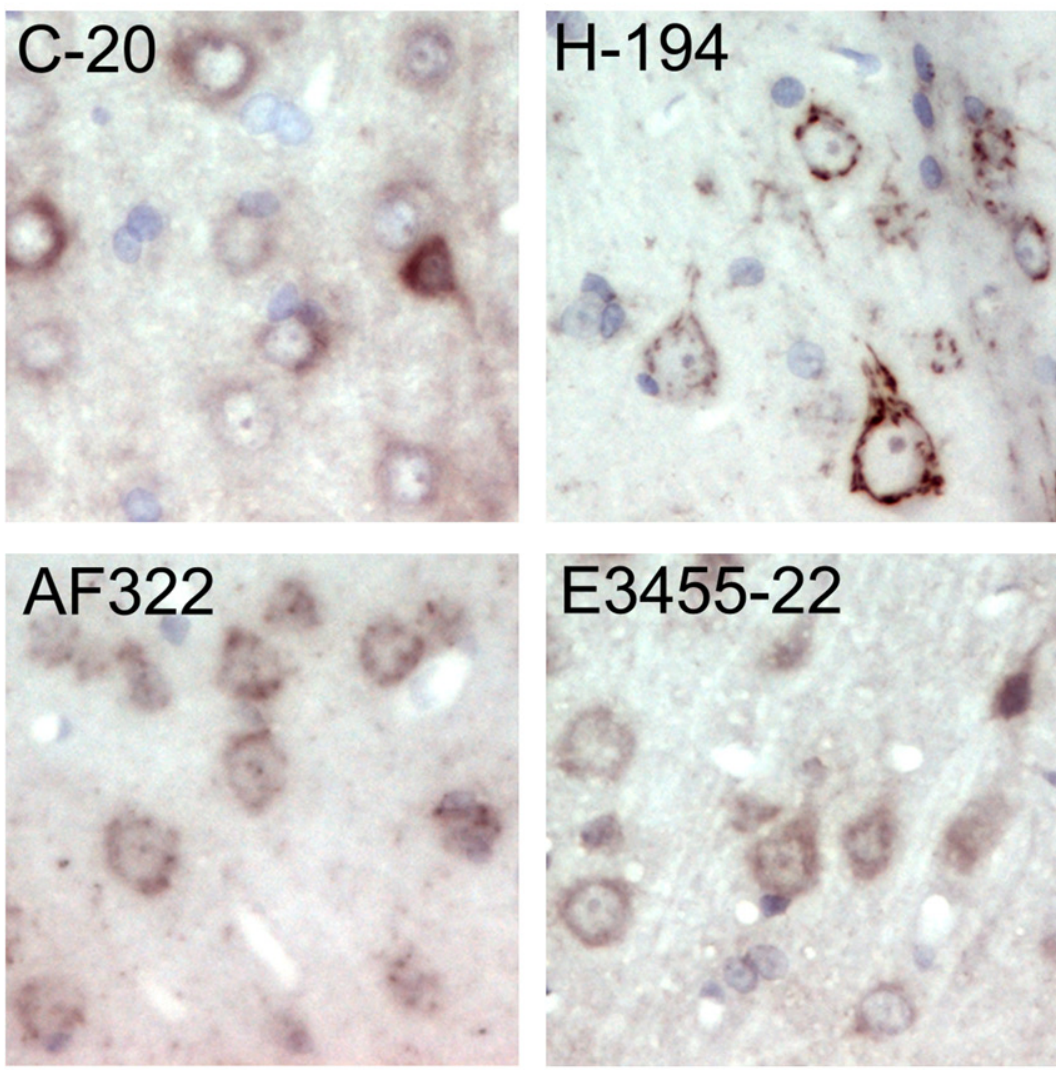

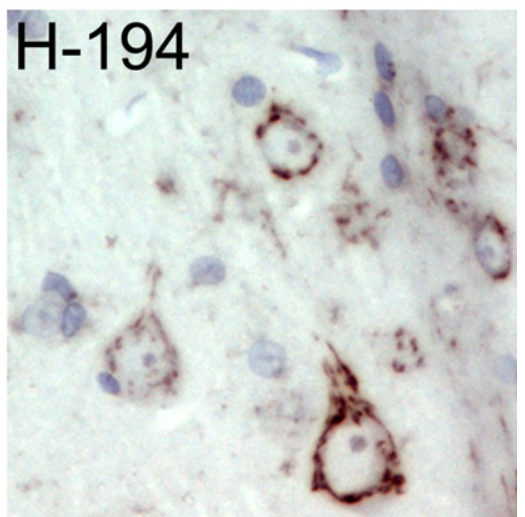

Hippocampus CA1

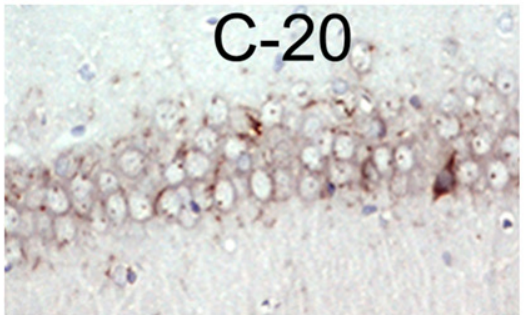

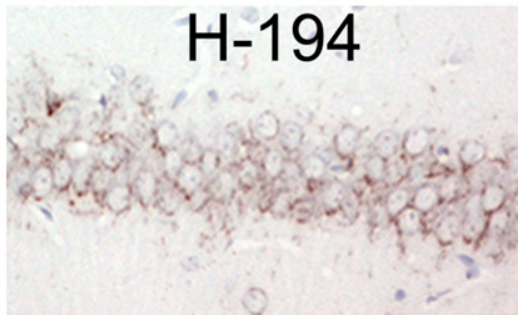

(C)

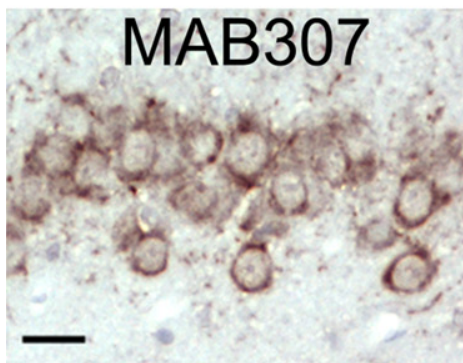

Hippocampus CA3

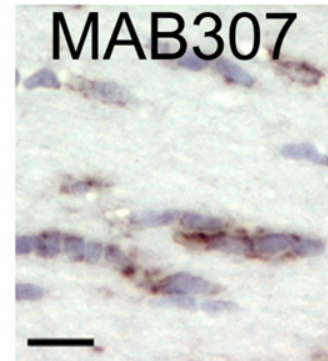

Corpus callosum

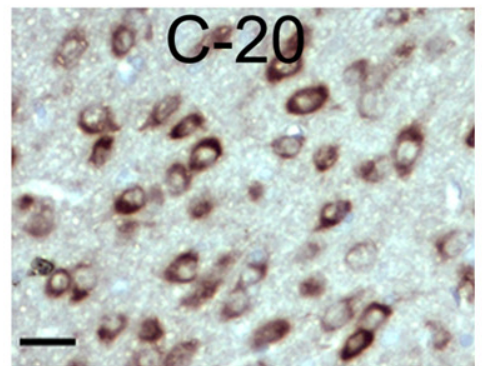

Dorsomedial thalamic nucleus

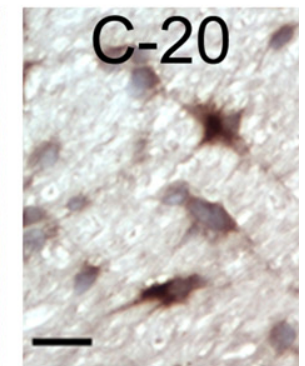

Optic chiasm

Fig. 3. Immunohistochemical staining of rat brain sections. Micrographs showing paraffin sections of rat brain immunohistochemically labelled with six different anti-EPOR antibodies. (A) Staining of sections from the neocortex. (B) Staining of sections from the hippocampal CA1 region. (C) Examples of variations in specific staining patterns with different antibodies. MAB307 intensely stained neurons in the CA3 region as well as oligodendrocyte-like cells in corpus callosum. C-20 showed intense immunostaining of dorsomedial thalamic nucleus as well as astrocytes in the optic chiasm. Scale bar: $25 \mu \mathrm{m}$. 

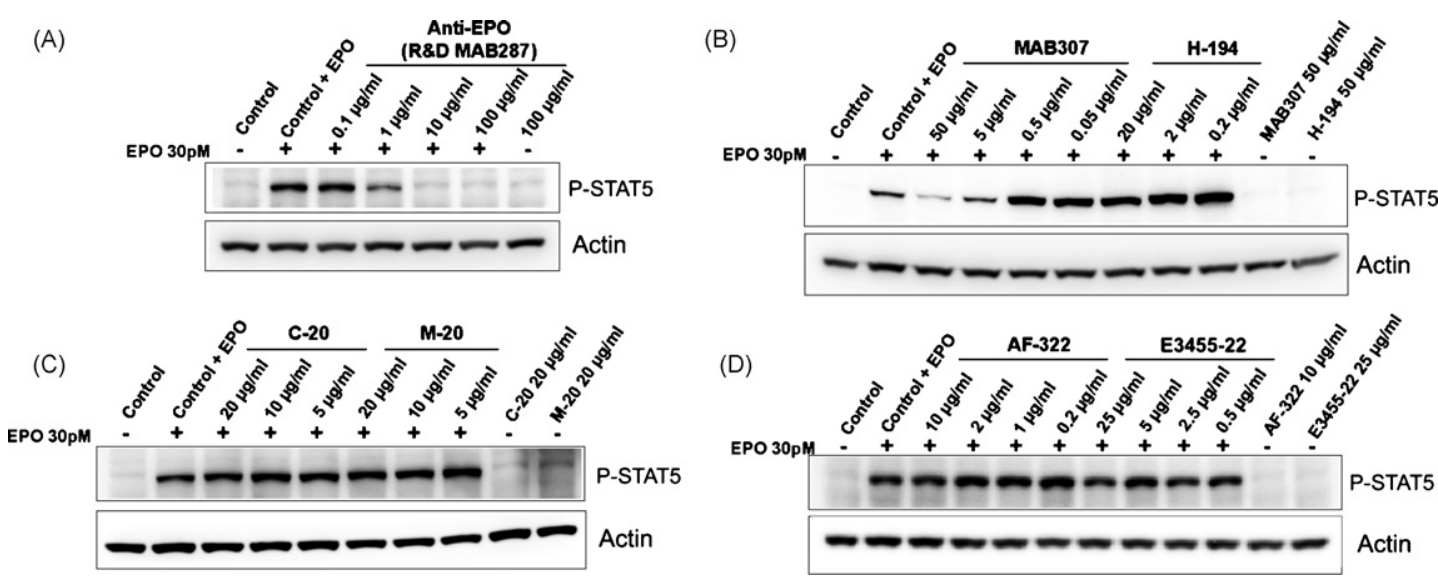

Fig. 4. Antibody-mediated inhibition of EPOR signalling. Test of inhibition of EPO-mediated signalling in UT-7 cells with anti-EPOR antibodies. UT-7 cells were preincubated with anti-EPOR antibodies for $30 \mathrm{~min}$ at the concentrations indicated and then stimulated with EPO for 15 min at $37^{\circ} \mathrm{C}$ before lysis. Phosphorylation of STAT5 was determined by Western blotting of the cell lysates. (A). An anti-EPO antibody was used as a positive control for blockade of EPO-mediated signalling. (B-D) The different anti-EPOR antibodies were tested at the concentrations indicated with or without stimulation with $30 \mathrm{pM} \mathrm{EPO.}$

When testing the antibodies for their ability to recognise endogenously expressed EPOR in hematopoietic UT-7 cells, we detected a range of differently sized protein bands. In hematopoietic late stage progenitor cells two major forms of the EPOR have been identified: the soluble form of about $30 \mathrm{kDa}$, and the mature membrane-bound form of about $50-70 \mathrm{kDa}$ (Kuramochi et al., 1990; Nakamura et al., 1992; Fujita et al., 1997). In the UT-7 cell line, the EPOR gene has been amplified to seven to eight copies resulting in a relatively high expression level of the EPOR, but contrary to other EPO-dependent leukemic cell lines, the EPOR gene in UT-7 cells is not disrupted in regions affecting splicing or amino acid sequence (Chretien et al., 1994). We would therefore expect lysates from these cells to produce a single band of the mature EPOR by Western blotting. However, this was not the case with any of the antibodies tested here. In line with our work, recent work by Elliott et al., 2006 has demonstrated clear differences in the specificity of different anti-EPOR antibodies in Western blotting. This study also included the three Santa Cruz antibodies C-20, M-20 and H-194, and they were able to demonstrate that the $\mathrm{C}-20$ and $\mathrm{H}-194$ antibodies both recognised proteins unrelated to the EPOR but of similar size of the EPOR (Elliott et al., 2006). One of these proteins was identified as the heat shock protein 70 (HSP70), which is of approximately the same molecular weight as the EPOR, and which like the EPOR might be upregulated after ischemic stress or trauma (Weinstein et al., 2004). Indeed, several studies have shown an increased staining with Santa Cruz anti-EPOR antibodies in the brain after ischemia (Bernaudin et al., 1999; Castillo-Melendez et al., 2005; Sairanen et al., 2006; Siren et al., 2001; Sola et al., 2005; Wen et al., 2004). These studies should be supported by the use of other techniques, as it has recently been shown that the use of the C-20 antibody in a line of other studies has lead to erroneous conclusions on EPOR expression in human carcinomas (Brown et al., 2006).

In our hands, immunohistochemical studies produced a variety of different staining patterns, however, there was a general tendency towards a broad immunoreactivity in neurons. Solely the M-20 resulted in a restricted staining pattern with only a fraction of neurons being positive. This is in accordance with a recent study in which only very sparse and scattered EPOR immunoreactivity was detected in the normal human brain when staining with the M-20 antibody (Sairanen et al., 2006). However, Elliott et al. found that despite the fact that the M-20 antibody showed specific recognition in immunoblotting, the antibody still stained EPOR-knockout tissue by immunohistochemistry implying that also this antibody should be used with caution. The C-20, MAB307, AF-322 and E3455-22 antibodies all exhibited some degree of nuclear staining, which might be an indication of unspecific staining.

Studies on immunohistochemical localisation of EPOR in the adult brain generally do not agree on the cellular localisation of the EPOR. Some studies show immunoreactivity to be restricted to neurons (Lewczuk et al., 2000; Sairanen et al., 2006), others find staining predominantly in astrocytes (Juul et al., 1998), yet others detect staining in both cell types (Bernaudin et al., 1999; Siren et al., 2001), and one study showed EPOR immunoreactivity to be located primarily to brain endothelial cells (Pillai and Mahadik, 2006). We suspect some of these discrepancies to be due to differences in antibodies used. Unfortunately many studies do not specify the identity of the anti-EPOR antibodies used. Some studies, based on the use of the C-20 antibody, report on EPOR expression in astrocytic endfeet around capillaries in the white matter of brain and spinal cord (Brines et al., 2000; Celik et al., 2002; Eid et al., 2004; Siren et al., 2001). In our hands, we observed a similar staining of astrocytic cell bodies and endfeet in both human and rat brain when applying the C-20 antibody. Notably, this staining was only observed with the C-20 antibody.

We have further investigated the possible usefulness of EPOR antibodies as EPOR antagonists. Our data show that antibodies, which are directed against the extracellular domain of the receptor, as are the MAB307, H-194, AF-322 and the E345522 antibody, cannot per se be expected to block activation of the EPOR, since only the MAB307 reduced EPO-mediated signalling in UT-7 cells. Several studies have employed anti-EPOR antibodies as functional EPOR antagonists without preceding validation of the blocking effects of the antibodies used 
(Campana et al., 1998; Keswani et al., 2004; Lee et al., 2004; Liu et al., 2006; Martinez-Estrada et al., 2003; Park et al., 2006; Ruscher et al., 2002; Signore et al., 2006; Stuckmann et al., 2003). In four cases, unspecified Santa Cruz antibodies have been applied (Liu et al., 2006; Keswani et al., 2004; Ruscher et al., 2002; Stuckmann et al., 2003) and, surprisingly, in two cases the Santa Cruz M-20 antibody directed against the intracellular domain of the EPOR was applied as an EPOR antagonist (Martinez-Estrada et al., 2003; Signore et al., 2006). Based on the epitope specificities and our functional data from the STAT5 assay, it must be assumed that effects induced by application of these anti-EPOR antibodies are not necessarily due to blocking of the EPO-EPOR interaction. In this context, it should be kept in mind that antibodies are frequently stored in solutions containing up to $15 \mathrm{mM}$ sodium azide. Azide may have substantial impact and toxic effects on cell cultures even at concentrations as low as $15 \mu \mathrm{M}$ (O'Riordan et al., 2000). Sodium azide can be avoided by applying a buffer change on the antibodies, as we have done here.

In summary, we encourage that these antibodies are used with caution, and that conclusions should not be drawn from the use of these antibodies alone. The production and thorough characterisation of new and more specific anti-EPOR antibodies is a major challenge for the future.

\section{Acknowledgements}

We thank Kirsten Jørgensen, Pia Møller-Carstensen and Annette Bjørn for excellent technical assistance and Dr Lars Østergaard Pedersen for helpful discussions.

\section{References}

Akimoto $\mathrm{T}$, Kusano $\mathrm{E}$, Inaba $\mathrm{T}$, Iimura $\mathrm{O}$, Takahashi $\mathrm{H}$, Ikeda $\mathrm{H}$, et al Erythropoietin regulates vascular smooth muscle cell apoptosis by a phosphatidylinositol 3 kinase-dependent pathway. Kidney Int 2000;58:269-82.

Bernaudin M, Marti HH, Roussel S, Divoux D, Nouvelot A, MacKenzie ET, et al. A potential role for erythropoietin in focal permanent cerebral ischemia in mice. J Cereb Blood Flow Metab 1999;19:643-51.

Brines M, Cerami A. Emerging biological roles for erythropoietin in the nervous system. Nat Rev Neurosci 2005;6:484-94.

Brines ML, Ghezzi P, Keenan S, Agnello D, de Lanerolle NC, Cerami C, et al Erythropoietin crosses the blood-brain barrier to protect against experimental brain injury. Proc Natl Acad Sci USA 2000;97:10526-31.

Brown WM, Maxwell P, Graham AN, Yakkundi A, Dunlop EA, Shi Z, et al. Erythropoietin receptor expression in non-small cell lung carcinoma: a question of antibody specificity. Stem Cells 2006; [Epub ahead of print].

Buus S, Stryhn A, Winther K, Kirkby N, Pedersen LO. Receptor-ligand interactions measured by an improved spun column chromatography technique. A high efficiency and high throughput size separation method. Biochim Biophys Acta 1995;1243:453-60.

Campana WM, Misasi R, O'Brien JS. Identification of a neurotrophic sequence in erythropoietin. Int J Mol Med 1998;1:235-41.

Castillo-Melendez M, Yan E, Walker DW. Expression of erythropoietin and its receptor in the brain of late-gestation fetal sheep, and responses to asphyxia caused by umbilical cord occlusion. Dev Neurosci 2005;27:220-7.

Celik M, Gokmen N, Erbayraktar S, Akhisaroglu M, Konakc S, Ulukus C, et al. Erythropoietin prevents motor neuron apoptosis and neurologic disability in experimental spinal cord ischemic injury. Proc Natl Acad Sci USA 2002;99:2258-63
Chretien S, Moreau-Gachelin F, Apiou F, Courtois G, Mayeux P, Dutrillaux B, et al. Putative oncogenic role of the erythropoietin receptor in murine and human erythroleukemia cells. Blood 1994;83:1813-21.

D'Andrea AD, Zon LI. Erythropoietin receptor. Subunit structure and activation. J Clin Invest 1990;86:681-7.

Eid T, Brines ML, Cerami A, Spencer DD, Kim JH, Schweitzer JS, et al. Increased expression of erythropoietin receptor on blood vessels in the human epileptogenic hippocampus with sclerosis. J Neuropathol Exp Neurol 2004;63:73-83.

Elliott S, Busse L, Bass MB, Lu H, Sarosi I, Sinclair AM, et al. Anti-Epo receptor antibodies do not predict Epo receptor expression. Blood 2006;107:1892-5.

Fujita M, Takahashi R, Kitada K, Watanabe R, Kitazawa S, Ashoori F, et al. Alternative splicing of the erythropoietin receptor gene correlates with erythroid differentiation in rat hematopoietic and leukemic cells. Cancer Lett 1997; 112:47-55

Helboe L, Moller M, Norregaard L, Schiodt M, Stidsen CE. Development of selective antibodies against the human somatostatin receptor subtypes sst1sst5. Brain Res Mol Brain Res 1997;49:82-8.

Juul SE, Anderson DK, Li Y, Christensen RD. Erythropoietin and erythropoietin receptor in the developing human central nervous system. Pediatr Res 1998;43:40-9.

Keswani SC, Buldanlioglu U, Fischer A, Reed N, Polley M, Liang H, et al. A novel endogenous erythropoietin mediated pathway prevents axonal degeneration. Ann Neurol 2004;56:815-26.

Komatsu N, Nakauchi H, Miwa A, Ishihara T, Eguchi M, Moroi M, et al. Establishment and characterization of a human leukemic cell line with megakaryocytic features: dependency on granulocyte-macrophage colonystimulating factor, interleukin 3, or erythropoietin for growth and survival. Cancer Res 1991;51:341-8.

Kuramochi S, Ikawa Y, Todokoro K. Characterization of murine erythropoietin receptor genes. J Mol Biol 1990;216:567-75.

Lee SM, Nguyen TH, Park MH, Kim KS, Cho KJ, Moon DC, et al. EPO receptor-mediated ERK kinase and NF-kappaB activation in erythropoietinpromoted differentiation of astrocytes. Biochem Biophys Res Commun 2004;320:1087-95.

Leist M, Ghezzi P, Grasso G, Bianchi R, Villa P, Fratelli M, et al. Derivatives of erythropoietin that are tissue protective but not erythropoietic. Science 2004;305:239-42.

Lewczuk P, Hasselblatt M, Kamrowski-Kruck H, Heyer A, Unzicker C, Siren $\mathrm{AL}$, et al. Survival of hippocampal neurons in culture upon hypoxia: effect of erythropoietin. Neuroreport 2000;11:3485-8.

Liu R, Suzuki A, Guo Z, Mizuno Y, Urabe T. Intrinsic and extrinsic erythropoietin enhances neuroprotection against ischemia and reperfusion injury in vitro. J Neurochem 2006;96:1101-10.

Martinez-Estrada OM, Rodriguez-Millan E, Gonzalez-De VE, Reina M, Vilaro S, Fabre M. Erythropoietin protects the in vitro blood-brain barrier against VEGF-induced permeability. Eur J Neurosci 2003;18:2538-44.

Nakamura Y, Komatsu N, Nakauchi H. A truncated erythropoietin receptor that fails to prevent programmed cell death of erythroid cells. Science 1992;257:1138-41.

O'Riordan TC, Buckley D, Ogurtsov V, O'Connor R, Papkovsky DB. A cell viability assay based on monitoring respiration by optical oxygen sensing. Anal Biochem 2000;278:221-7.

Park MH, Lee SM, Lee JW, Son DJ, Moon DC, Yoon dY, et al. ERKmediated production of neurotrophic factors by astrocytes promotes neuronal stem cell differentiation by erythropoietin. Biochem Biophys Res Commun 2006;339:1021-8.

Pillai A, Mahadik SP. Differential effects of haloperidol and olanzapine on the expression of erythropoietin and its receptor in rat hippocampus and striatum. J Neurochem 2006;98:1411-22.

Richmond TD, Chohan M, Barber DL. Turning cells red: signal transduction mediated by erythropoietin. Trends Cell Biol 2005;15:146-55.

Ruscher K, Freyer D, Karsch M, Isaev N, Megow D, Sawitzki B, et al. Erythropoietin is a paracrine mediator of ischemic tolerance in the brain: evidence from an in vitro model. J Neurosci 2002;22:10291-301.

Sairanen T, Karjalainen-Lindsberg ML, Paetau A, Ijas P, Lindsberg PJ. Apoptosis dominant in the periinfarct area of human ischemic stroke-a possible target of antiapoptotic treatments. Brain 2006;129:189-99. 
Savino C, Pedotti R, Baggi F, Ubiali F, Gallo B, Nava S, et al. Delayed administration of erythropoietin and its non-erythropoietic derivatives ameliorates chronic murine autoimmune encephalomyelitis. J Neuroimmunol 2006;172:27-37.

Schneider H, Chaovapong W, Matthews DJ, Karkaria C, Cass RT, Zhan H, et al. Homodimerization of erythropoietin receptor by a bivalent monoclonal antibody triggers cell proliferation and differentiation of erythroid precursors. Blood 1997;89:473-82.

Signore AP, Weng Z, Hastings T, Van Laar AD, Liang Q, Lee YJ, et al. Erythropoietin protects against 6-hydroxydopamine-induced dopaminergic cell death. J Neurochem 2006;96:428-43.

Siren AL, Knerlich F, Poser W, Gleiter CH, Bruck W, Ehrenreich H. Erythropoietin and erythropoietin receptor in human ischemic/hypoxic brain. Acta Neuropathol (Berlin) 2001;101:271-6.

Sola A, Rogido M, Lee BH, Genetta T, Wen TC. Erythropoietin after focal cerebral ischemia activates the Janus kinase-signal transducer and activator of transcription signaling pathway and improves brain injury in postnatal day 7 rats. Pediatr Res 2005;57:481-7.

Stuckmann I, Evans S, Lassar AB, Erythropoietin. retinoic acid, secreted from the epicardium, are required for cardiac myocyte proliferation. Dev Biol 2003;255:334-49.

Sun Y, Zhou C, Polk P, Nanda A, Zhang JH. Mechanisms of erythropoietininduced brain protection in neonatal hypoxia-ischemia rat model. J Cereb Blood Flow Metab 2004;24:259-70.

Wakao H, Harada N, Kitamura T, Mui AL, Miyajima A. Interleukin 2 and erythropoietin activate STAT5/MGF via distinct pathways. EMBO J 1995;14:2527-35.

Weinstein PR, Hong S, Sharp FR. Molecular identification of the ischemic penumbra. Stroke 2004;35:2666-70.

Wen TC, Rogido M, Genetta T, Sola A. Permanent focal cerebral ischemia activates erythropoietin receptor in the neonatal rat brain. Neurosci Lett 2004;355:165-8. 